\title{
SENTIDOS DE ENSINO DE LEITURA REVELADOS EM OBRAS DE ANNE- MARIE CHARTIER E SUAS RELAÇÕES COM OS SABERES DA DOCÊNCIA FABRICADOS NO COTIDIANO ESCOLAR
}

\author{
MEANINGS OF TEACHING READING REVEALED IN WORKS BY ANNE-MARIE \\ CHARTIER AND THEIR RELATIONS WITH TEACHING KNOWLEDGE PRODUCED IN \\ EVERYDAY SCHOOL LIFE
}

\section{JUEGA EN LA RECREACIÓN: ACCIONES VOLITIVAS EN TEXTOS ESCRITOS POR NIÑOS DE TERCER AÑO DE EDUCACIÓN ELEMENTAL}

\author{
Priscila Maria Vieira dos Santos Magalhães ${ }^{1}$ \\ Crislainy de Lira Gonçalves ${ }^{2}$ \\ Lucinalva Andrade Ataide de Almeida ${ }^{3}$
}

\begin{abstract}
Resumo: Este ensaio objetivou evidenciar sentidos do ensino da leitura e suas relações com os saberes docentes. Evidenciamos sentidos de leitura como decifração, recepção e interação, os quais revelam o movimento de complexificação da leitura em nível conceitual e pragmático.
\end{abstract}

Palavras-chave: Sentidos de ensino da leitura; saberes docentes; cotidiano.

\begin{abstract}
This article aimed to highlight the meanings of teaching reading and its relationship with teaching knowledge. We evidence reading meanings such as deciphering, reception and interaction, which reveal the movement of complexification of reading at a conceptual and pragmatic level.
\end{abstract}

Keywords: Reading teaching senses; teaching knowledge; daily.

Resumen: Este artículo tuvo como objetivo resaltar los significados de la enseñanza de la lectura y su relación con la enseñanza del conocimiento. Evidenciamos la lectura de significados como desciframiento, recepción e interacción, que revelan el movimiento de complejificación de la lectura a nivel conceptual y pragmático.

Palabras clave: Lectura, enseñanza de los sentidos; enseñanza del conocimiento; diario.

\section{Introdução}

O presente ensaio teórico se insere no campo dos estudos que versam sobre o ensino da leitura e escrita na escola. Fruto do Curso Escola de Altos Estudos ${ }^{4}$, este trabalho teve por principal objetivo evidenciar sentidos de ensino de leitura revelados em obras de Anne-Marie Chartier e suas relações com os saberes da docência fabricados cotidianamente pelos professores. Justificamos que a centralidade dada ao pensamento da referida autora se dá por reconhecermos a relevância e contribuição que a mesma tem tido no debate internacional acerca

\footnotetext{
${ }^{1}$ Programa de Pós-Graduação em Educação da Universidade Federal de Pernambuco

${ }^{2}$ Programa de Pós-Graduação em Educação da Universidade Federal de Pernambuco

${ }^{3}$ Programa de Pós-Graduação em Educação Contemporânea da Universidade Federal de Pernambuco

${ }^{4}$ Curso promovido no âmbito do Projeto "Currículo e avaliação, leitura e escrita: diálogos entre Brasil/França e Brasil/Portugal”, ofertado pelo Programa de Pós-Graduação em Educação Contemporânea (PPGEduc), do Centro Acadêmico do Agreste (CAA), da Universidade Federal de Pernambuco (UFPE), e fomentado pela Coordenação de Aperfeiçoamento de Pessoal de Nível Superior (CAPES). O curso, sob a coordenação do professor Alexandro Silva e vice-coordenação Lucinalva Almeida, teve como docente convidada a professora Dr. ${ }^{a}$ Anne-Marie Chartier.
} 
das perspectivas históricas e teóricas da leitura e escrita, das metodologias de ensino e dos saberes científicos e da ação que orientam as práticas cotidianas na escola.

Para subsidiar nossas compreensões recorremos a uma abordagem de orientação qualitativa, em que a Análise do Discurso (doravante AD) na perspectiva de Orlandi (2010), constituiu-se em abordagem privilegiada. A escolha por esta lente teórico-metodológica se deu por entendermos que a AD melhor possibilitava perceber a polissemia discursiva inscrita na multiplicidade de sentidos acerca do ensino de leitura na escola e dos saberes da docência que o atravessa. Assim, a AD foi ferramenta elementar na compreensão dos sentidos circunscritos na atualidade, bem como na percepção de suas relações com outros dizeres já ditos em outros contextos sócio-históricos, uma vez que como aponta Chartier (2016), historicamente diferentes práticas de leitura e escrita têm coexistido na sociedade. Assim, ao entendermos discurso enquanto prática, reconhecemos que a produção discursiva em torno da leitura e escrita revela resquícios e coexistência de diferentes sentidos em torno do que significa ler e escrever ao longo da história da humanidade.

Reconhecendo a historicidade e contingencialidade discursiva que ergue os sentidos de leitura e escrita, compreendemos que o saber ler e escrever "de uma época remete a um modelo dominante que pode ser imposto apenas por autoridades reconhecidas: a Igreja no século XVII, os ministros da instrução pública no século XIX, as instâncias internacionais de avaliação no final do século XX” (CHARTIER, 2016, p. 289). Em outras palavras, o saber ler e escrever de um determinado período está intimamente ligado às definições dadas por sujeitos que, na posição discursiva (ORLANDI, 2010) que ocupam e na formação ideológica que se inserem, galgam de poder para definir as bases do que significa ler e escrever socialmente.

Contudo, ao tomarmos a AD como lente teórica-metodológica, compreendemos que "[...] os sentidos não estão só nas palavras, nos textos, mas na relação com a exterioridade, nas condições em que eles são produzidos" (ORLANDI, 2010, p. 28), e reconhecemos a necessidade de lançarmos um olhar não apenas para tais sentidos, mas também para sua exterioridade discursiva, isto é, para os saberes docentes que atravessam a tessitura dos sentidos de leitura na escola.

Em busca de evidenciarmos nesse complexo discursivo sentidos do ensino de leitura que nos possibilitassem precariamente caracterizar esse campo analítico, procuramos nos afastar de análises essencializantes dos fenômenos socioeducacionais aqui enfocados, entendendo, assim, a partir de enfoques discursivos, que os fenômenos sociais "[...] não têm uma única forma de abordar, de descrever, de explicar; não estão sujeitos a uma relação simples de causalidade; não se constituem por um único investimento de sentido [...]" (BURITY, 2014, p. 66).

Nessa direção, reconhecendo as múltiplas formas de abordar e significar os fenômenos sociais, elegemos enquanto ponto de partida analítica duas dimensões interdependentes constituintes a produção dos sentidos de leitura, a saber: as próprias especificidades sociolinguísticas da leitura e os saberes docentes que atravessam seu ensino. A partir dessas dimensões, organizamos esse texto em três momentos. Inicialmente evidenciamos e discutimos os principais sentidos de leitura e escrita revelados em obras de Anne-Marie Chartier. Em um segundo momento, prosseguimos tecendo algumas reflexões em torno dos saberes práticos e teóricos que constituem tais sentidos e, por fim, elencamos algumas considerações finais a respeito do estudo.

\section{Sentidos de leitura e escrita revelados em obras de Anne-Marie Chartier}

Ao nos aproximarmos de expoentes que discutem a leitura como fenômeno linguístico sócio-histórico como, Anne-Marie Chartier, percebemos que ao longo dos tempos os sentidos atribuídos a leitura têm sofrido profundas transformações resultantes da evolução das compreensões e das práticas de leitura vivenciadas em diferentes espaços sociais, a exemplo da 
escola. Evidenciamos, desse modo, o movimento de complexificação desses sentidos não só em nível conceitual, como também pragmático.

De tradições centradas puramente em disciplinas, às tradições orientadas segundo a lógica de competência (CHARTIER, 2015), a leitura na escola tem se revestido de sentidos diversos, como: leitura como decifração, leitura como recepção de textos desconhecidos e leitura como interação (CHARTIER, 2016).

Caracterizada pela oralização de palavras, decifração de sílabas, ênfase na memória oral e por exercícios mecânicos tediosos compostos por "colonnes de syllabes, des plus simples (ba, be, bi, bo, bu) aux plus complexes [...], puis des listes de mots classés selon leur longueur (une, deux, trois syllabes), enfin des suites de phrases qui ne composent aucun texte" 2015, p. 111), o sentido de leitura como decifração emerge em um contexto social no qual a demanda de apropriação de textos e saberes litúrgicos, dogmáticos e efêmeros, outorgava o título de "sujeito leitor" aqueles que pela simples memorização e recitação de textos conseguiam adentrar à cultura letrada.

O olhar analítico em torno das discussões produzidas por Anne-Marie Chartier nos possibilitou evidenciar, também, o sentido de leitura como recepção, o qual remete a um contexto sócio-histórico no qual ler reduzia-se ao ato de "[...] selecionar, ao longo da leitura, as informações que permitirão a construção de uma representação global do texto. Pode-se assim ter acesso ao pensamento do outro, o que não compromete de forma alguma o leitor" (CHARTIER, 2016, p. 291). Nesse sentido, a prática de leitura era significada como ato unilateral, desvencilhada dos conhecimentos prévios e da capacidade de construção de significados do leitor.

Contudo, na conjuntura sócio-cultural francesa, verifica-se que a emergência do sentido de leitura como recepção cumpriu o propósito de rompimento do monopólio dos textos religiosos nos espaços escolares e sociais, contribuindo para o acesso da população (primeiro as elites e depois as camadas populares) a textos julgados como fúteis (CHARTIER, 2016).

Diferenciando-se ${ }^{6}$ dos sentidos já mencionados, identificamos a emergência do sentido de leitura como interação, no qual o ato de ler passou a ser compreendido como processo de interação entre o leitor e o texto. De caráter funcional, esse sentido inaugura uma nova relação com a leitura, na qual para além de comunicar, ler passou a significar saber tratar diferentes tipos de textos e construir múltiplas competências de compreensão desses (CHARTIER, 2015).

Com esse sentido, um novo papel é atribuído ao aluno leitor. De receptáculo de uma língua "coisificada", ele passa a ser percebido como leitor ativo que age sob os textos à medida que mobiliza seus conhecimentos de mundo para processar, elaborar, prever e construir significados para além da superfície textual.

Destarte, frente aos sentidos de leitura evidenciados, vislumbramos ser eles atravessados por uma memória discursiva (ORLANDI, 2010, p. 31), por um "saber discursivo que torna possível todo dizer e que retorna sob a forma do pré-construído". Assim, os sentidos de leitura como decifração, recepção e interação, indicam constituírem-se a partir de discursos que apesar de já serem ditos em outros contextos sócio-históricos, ainda na contemporaneidade revelam suas marcas sobre os discursos e as práticas empreendidas nas escolas. Como destaca Chartier (2016), na história da escola vários discursos atravessaram o ensino da leitura: "o discurso religioso sobre a necessidade de dar a todos um contato direto com as escrituras dos textos sagrados, o discurso

\footnotetext{
5 “colunas de sílabas, das mais simples (ba, be, bi, bo, bu) às mais complexas [...], a seguir listas de palavras classificadas de acordo com sua extensão (uma, duas, três sílabas), finalmente sequências de frases que não compõem nenhum texto". ${ }^{6}$ Apesar de reconhecermos suas especificidades em relação a outros sentidos, percebemos que o sentido de leitura como interação não rompe por completo com os sentidos que lhe antecederam, visto que como aponta Solé (1998, p. 23), "este modelo pressupõe uma síntese e uma integração de outros enfoques que foram elaborados ao longo da história para explicar o processo de leitura".
} 
político sobre a necessidade de uma alfabetização para a emancipação, que permitisse aos cidadãos conhecer as leis e ler os jornais" (CHARTIER, 2010, p. 3).

\section{Saberes teóricos e da ação (re)inventados no cotidiano escolar}

Ao reconhecermos o caráter cíclico dos diferentes sentidos de leitura na sociedade e na escola, entendemos que é no espaço escolar que melhor visualizamos o movimento discursivo e pragmático destes. Sobretudo, partimos do pressuposto que é no âmbito dos saberes da docência e das práticas de ensino realizadas pelos professores que mais fortemente esses sentidos encontram eco.

Assim, entendemos que no cotidiano escolar, frente as diversas necessidades de aprendizagens discentes e às suas visões de mundo, de educação e de língua, os professores mobilizam uma série de saberes científicos e, principalmente, saberes da ação, para orientar e subsidiar o ensino da leitura na sala de aula.

Apesar de defendermos a interdependência desses saberes, percebemos que os mesmos guardam especificidades que não podem ser tomadas como sinônimas ou hierárquicas, pois como destaca Chartier (2010, p. 13),

Saberes e teorias não são coisas idênticas. Constato que os professores se servem de um número considerável de 'saberes científicos' em suas salas de aula, mas eles nem sempre têm consciência disso, porque certos saberes já pertencem tanto a suas categorias de pensamento e de sua cultura escolar que eles os utilizam como se fossem realidades naturais.

Nessa linha, compreendemos que os saberes científicos produzidos nos centros acadêmicos e, por vezes, verticalmente transferidos para "uso e consumo" (CERTEAU, 2014) nas escolas, têm sua gênese não apenas no campo teórico, mas, também, nas "práticas comuns" cotidianas do ensino da leitura fabricadas pelos sujeitos ordinários da escola, apesar da cegueira epistemológica que insiste em silenciar as "mil maneiras" astuciosas (CERTEAU, 2014) de pensar-praticar o ensino da leitura no espaço escolar. Como ressalta Chartier (2005, p. 24) os saberes da ação "permanecem, a maior parte do tempo, invisíveis e desconhecidos dos próprios indivíduos que os praticam".

Nessa relação de uso e consumo de "produtos" historicamente prescritivos das ações docentes, como programas de ensino, livros, cadernos de exercícios e manuais do professor (CHARTIER, 2010), vislumbramos a não reprodução didática do que fora pensado pelos discursos científico-acadêmicos, posto que "esta transferência de um mundo a outro, não é o resultado de uma transposição didática, [...], mas, sim, de uma apropriação coletiva dos saberes. A cultura docente manterá aqueles saberes que são úteis e os demais permanecerão no mundo dos pesquisadores" (CHARTIER, 2010, p. 15).

Ao consumir apenas os saberes que são úteis em seus cotidianos, os professores revelam que "os conceitos científicos não são utilizáveis na sala de aula pelo simples fato de serem 'científicos'. [...] sua recepção depende dos contextos escolares serem mais ou menos favoráveis" (CHARTIER, 2010, p. 14). Desse modo, a relação que os professores estabelecem com os discursos científicos está intimamente ligada à vitalidade das diversas situações pedagógicas de ensino-aprendizagem em emergência nos cotidianos escolares.

De modo específico, se lançarmos um olhar para a história do ensino de leitura em diferentes realidades socioculturais, percebemos as contribuições ${ }^{7}$ dos saberes científicos para reconfiguração e transformação das práticas de ensino tecidas na escola. Com contribuições significativas, os

\footnotetext{
${ }^{7}$ No Brasil, em meados da década de 1970, destacam-se as contribuições dos saberes científicos da Psicogênese da Escrita cunhada por Emília Ferreiro e Ana Teberosky acerca da aquisição das habilidades de leitura e escrita.
} 
saberes científicos "[...]levaram os professores a perceber a complexidade dos elementos que entram em jogo na aprendizagem da leitura e da escrita" (CHARTIER, 2010, p. 12).

Apesar de reconhecida a relevância de tais saberes, o cotidiano escolar - aqui entendido como espaço-tempo de (re)invenção - nos revela que, por vezes, as práticas cotidianas realizadas pelos professores indicam certa autonomia em relação ao saber científico emergido nas instâncias "oficiais" de produção do conhecimento.

Tal "autonomia" não reside na negação ou ruptura brutal ao discurso oficial direcionado a fixação de sentidos normatizantes de ensino de leitura na escola, mas, sim, na possibilidade de "negociar de maneira parcialmente dita, parcialmente sabida; sua maneira de fazer, a uma margem de jogo que autoriza uma diversidade regulada e limitada de práticas possíveis" (CHARTIER, 2000a, p. 165). Ao negociar maneiras autorizadas e maneiras "clandestinas" (CERTEAU, 2014) de ensino da leitura, "as práticas aparecem, por tanto, como articuladoras de escolhas múltiplas" (CHARTIER, 2000a, p. 165) emergidas de dois mundos discursivos inter-relacionais: o mundo dos praticantes e o mundo dos teóricos (CHARTIER, 2007b).

Apesar da aparente ficção entre o dizer e o fazer instaurada pelo saber científico e da tentativa de cerceamento do falar dos praticantes do ensino da leitura a escola, vislumbramos que "[...] práticos falam, mas eles o fazem nas redes de trocas dialógicas permanentes, subjetivas, infindáveis, entrecruzadas. Se as práticas são mudas, quando elas estão desvinculadas de seus atores, os praticantes, por sua vez, não são mudos" (CHARTIER, 2007a, p. 13). Assim, apesar do discurso científico galgar de poder para cristalizar sentidos em torno do saber ler de cada época, sua mobilização não se dá indescritivelmente nas situações pedagógicas dos praticantes do cotidiano.

Quando lançamos um olhar para os produtos emergidos face aos discursos e saberes científicos, como as políticas nacionais/locais de alfabetização e currículo, os programas de leitura e escrita e recursos pedagógicos vendidos às secretarias estaduais e municipais de educação, os livros didáticos de Língua Portuguesa e seus respectivos manuais e a formação docente; evidenciamos o quanto estes são consumidos e (re)inventados de modos diversos pelos professores em sala de aula. Isto porque, é na escola, na relação entre os pares, que mais fortemente os discursos e saberes da ação ecoam. Como destaca Chartier (2007a, p. 16),

[...] ocorre que os colegas de trabalho falam a mesma linguagem mesmo se, claro, cada um digere as coisas a sua maneira. Podemos assim analisar as famosas 'receitas', nas quais o valor de uso garante o valor de troca, como sinal típico desse oral-prático que baliza as zonas de trocas possíveis: podemos trocar receitas se, e somente se, reconhecemos um campo comum de exercício, então com qualquer colega podemos sempre trocar propostas sobre a escola 'em geral'. O discurso oral ligado às práticas permite, desse modo, que os professores se identifiquem como um corpo de praticantes, embora cada um trabalhe sozinho na classe.

É, pois, no interior desse corpo de praticantes, num movimento de troca, que os professores entre si, por falarem a mesma "língua" e partilharem de contextos e demandas muito semelhantes, mobilizam saberes da ação e práticas coletivas que os auxiliam na cotidianidade do ensino de leitura em seus espaços de atuação.

Além dessa coletividade que orienta as trocas, os modos de consumo e a fabricação de maneiras de fazer próprias do professorado, seus saberes da ação são, ainda, fabricados a partir de seus tempos de atuação na docência. Desse modo, caso o professor seja novato ou expert na profissão, os seus modos de apropriação dos diferentes registros discursivos oficiais serão contrastantes (CHARTIER, 2000b), podendo conduzir os docentes iniciantes e menos seguros a adotar as "propostas "científicas" dos especialistas, esperando que elas produzam milagres" (CHARTIER, 2000b, p. 56), ou fundamentar o docente experiente a identificar os limites dos saberes enaltecidos teoricamente. 
Além de influenciar na leitura feita ao discurso oficial, tal prematuridade ou expertise profissional pode, ainda, implicar nos modos de consumos feitos as inovações pedagógicas que brutalmente chega as escolas. Assim, sob o argumento que as (in)competências dos professores seriam as causas da (baixa) qualidade do ensino (SARTI, 2008), o campo científico tem historicamente construído e atribuído uma imagem "reacionária" sobre aqueles que astuciosamente ousam questionar e burlar as "inovações" pedagógicas advindas do discurso oficial.

Ao criar uma imagem depreciativa dos professores, dos seus saberes e práticas, cria-se uma equivocada oposição entre prática tradicional e prática inovadora que, "parece recobrir uma análise de fato simplista: os professores recusam a inovação seja por convicção ideológica [...], seja pela preguiça profissional (acredita-se no ganho de eficácia, mas não se deseja fazer o investimento de energia que permitiria obtê-la)" (CHARTIER, 2000a, p. 163).

Se lançarmos um olhar mais atento sobre essa visão polarizadora e empobrecedora acerca de práticas significadas como "tradicionais/reacionárias" ou "inovadoras", percebemos o quanto os discursos que a balizam parecem funcionar como um mecanismo de antecipação (ORLANDI, 2010), no qual o discurso científico se antecipa a possíveis críticas que, porventura, argumentem que ele não consegue dá conta de todas as demandas didático-pedagógicas que atravessam o ensino da leitura e da escrita na escola. Dessa maneira, ao insistir em enunciados polarizantes como, "prática tradicionais" versus "práticas inovadoras", tal discurso "antecipa-se, assim, a seu interlocutor quanto ao sentido que suas palavras produzem" (ORLANDI, 2010, p. 39), intencionando regular os efeitos de sentido resultantes de sua produção discursiva.

Desse modo, se nos primórdios das investigações sobre o ensino da leitura e da escrita as razões do insucesso escolar das crianças foi, em um primeiro momento, atribuída "principalmente a causas extraescolares (a criança, a família, o ambiente social), em cujas explicações concorriam psicólogos (quociente intelectual insuficiente); psicanalistas (bloqueios psicoafetivos), neurologistas (dislexia) e sociólogos (fraca cultura escolar das famílias)" (CHARTIER, 2016, p. 279), e posteriormente aos métodos arcaicos de alfabetização; hoje tais causas têm recaído sobre os professores e suas práticas que, ao se mostrarem "resistentes" ao discurso da inovação e seus métodos "milagrosos" acabam contribuindo para perpetuação das dificuldades atravessadas no ensino de leitura.

Além de se antecipar em relação a possíveis "denúncias" de sua não onipotência na solução dos males que historicamente assolam o ensino da leitura na escola, e assim, tentar silenciar sua incompletude discursiva, a oposição "tradição/inovação" "mascara [...]a existência de toda uma série de ações profissionais ordinárias que constituem o tronco sobre o qual vêm se enxertar os estilos pedagógicos ou didáticos específicos, tradicionais ou inovadores" (CHARTIER, 2000a, p. 164). Assim, tal dicotomização silencia a ideia que para inovar, os professores dependem de contextos específicos favoráveis às tais mudanças e que a inovação nunca é uma maneira de recomeçar do zero (CHARTIER, 2000b), posto ter como ponto de partida um conjunto de práticas já consolidadas na cotidianidade da escola.

\section{Considerações finais}

A partir das reflexões aqui tecidas a respeito dos sentidos de ensino de leitura revelados em obras de Anne-Marie Chartier e suas relações com os saberes da docência, vislumbramos a emergência de diferentes sentidos de ensino de leitura, como: leitura como decifração, recepção e interação. Estes têm apontado para o movimento de complexificação da leitura em nível conceitual e pragmático, e para a redefinição do papel do aluno e do professor no espaço-tempo escolar.

Assim, evidenciamos que tal redefinição teve sua gênese no centro dos diferentes usos e funções sociais da leitura ao longo dos tempos, das demandas históricas em torno do ensino 
de leitura e a escrita na escola, de teorias explicativas e prescritivas das práticas de ensino, da formação docente, e dos saberes científicos e da ação que permeiam os procedimentos didáticos-metodológicos em sala de aula.

Evidenciamos, ainda, a relação de interdependência dos saberes científicos e da ação, contudo, percebemos o não determinismo das formas de apropriação desses saberes, posto que seus modos de consumo se constituem não em uma lógica de transposição didática, mas de apropriação coletiva e articuladora de múltiplos discursos.

Destarte, depreendemos que a relação dos sentidos de ensino de leitura e dos saberes da docência se dá ao passo que, em suas práticas de ensino cotidianas os professores revelam recorrer e fazer uso de sentidos de leitura que atendam a pluralidade de situações didáticas e de formação de seus contextos de atuação. Para mobilização desses sentidos, os docentes tomam por referência os saberes da ação emergidos em seus espaços profissionais e, apontam para o caráter astucioso e criador de suas artes de fazer (CERTEAU, 2014) cotidianas.

\section{Referências}

BURITY, Joanildo Albuquerque. Discurso, política e sujeito na teoria da hegemonia de Ernesto Laclau. In: SILVA, L. G. T.; COELHO G. B.; COSTA E. G.; FREITAS, F. C. (Org.) Pósestruturalismo e teoria do discurso: em torno de Ernesto Laclau. 2. ed. Porto Alegre: EDIPUCRS, 2014. p. 59-74.

CERTEAU, Michel de. A invenção do cotidiano: artes de fazer. 22. ed. Petrópolis: Vozes, 2014.

CHARTIER, Anne-Marie. Os três modelos da leitura entre os séculos XVI e XXI: como as práticas sociais transformam os métodos de ensino. Revista Brasileira de História da Educação, v. 16, n. 1, p. 253-295, jan./abr. 2016. Disponível em: http://www.periodicos.uem.br/ojs/index.php/rbhe/article/view/40774/pdf_108. Acesso em: 15 jul. 2021.

CHARTIER, Anne-Marie. La logique des compétences dans l'histoire de la lecture scolaire. Le Français Aujour D'Hui, v. 191, n. 4, p. 97-112, 2015. Disponível em: https://www.cairn.info/revuele-francais-aujourd-hui-2015-4-page-97.htm. Acesso em: 15 jul. 2021.

CHARTIER, Anne-Marie. Ensinar a ler e escrever, entre teoria e prática. 2010, p. 1-20. [Palestra 5 Semana da Educação da Fundação Victor Civita] Disponível em: https://novaescola.org.br/conteudo/1635/palestra-de-anne-marie-chartier-na-semana-daeducacao-2010. Acesso em: 15 jul. 2021.

CHARTIER, Anne-Marie. Ação docente: entre saberes práticos e saberes teóricos. In: CHARTIER, A-M. Práticas de leitura e escrita: história e atualidade. Belo Horizonte: Autêntica, 2007a. p. 1-19.

CHARTIER, Anne-Marie. A leitura e sua aquisição: modelos de ensino, modelos de aprendizagem. In: CHARTIER, A-M. Práticas de leitura e escrita: história e atualidade. Belo Horizonte: Autêntica, 2007b. p. 147-184

CHARTIER, Anne-Marie. Escola, culturas e saberes. In: XAVIER, L. N. et al. (Org.). Escola, culturas e saberes. Rio de Janeiro: FGV, 2005. p. 9-28. 
CHARTIER, Anne-Marie. Fazeres ordinários da classe: uma aposta para a pesquisa e para a formação. Educação e Pesquisa, v. 26, n. 2, p. 157-168, dez. 2000a. Disponível em: http://www.scielo.br/pdf/ep/v26n2/a11v26n2.pdf. Aceso em: 15 jul. 2021.

CHARTIER, Anne-Marie. Réussite, échec et ambivalence de l'innovation pédagogique: le cas de l'enseignement de la lecture. Recherche et Formation, n. 34, p. 41-56, déc. 2000b. Disponível em: $\quad$ http://ife.ens-lyon.fr/publications/edition-electronique/recherche-et-formation/RR03404.pdf. Acesso em: 15 jul. 2021.

ORLANDI, Eni. Análise de discurso: princípios e procedimentos. Campinas: Pontes, 2010.

SARTI, Flavia Medeiros. O professor e as mil maneiras de fazer no cotidiano escolar. Educação: Teoria e Prática, v. 18, n. 30, p. 47-65, jan./jun. 2008. Disponível em: http://hdl.handle.net/11449/106942. Acesso em: 15 jul. 2021.

SOLÉ, Isabel. Estratégias de leitura. Porto Alegre: ArtMed, 1998.

\section{Sobre as autoras}

Priscila Maria Vieira dos Santos Magalhães. Doutoranda no Programa de Pós-graduação em Educação pela Universidade Federal de Pernambuco (UFPE) / Centro de Educação (CE). Mestre pelo Programa de Pós-Graduação em Educação Contemporânea pela Universidade Federal de Pernambuco (UFPE) - Centro Acadêmico do Agreste (CAA). Integrante do Grupo de Pesquisa Discursos e Práticas Educacionais.

E-mail: priscilamagalhaesufpe@gmail.com.

Crislainy de Lira Gonçalves. Doutoranda na Programa de Pós Graduação em Educação da Universidade Federal de Pernambuco (UFPE) / Centro de Educação (CE). Mestre pelo Programa de Pós-Graduação em Educação Contemporânea pela Universidade Federal de Pernambuco (UFPE) - Centro Acadêmico do Agreste (CAA). Integrante do Grupo de Pesquisa Discursos e Práticas Educacionais.

E-mail: cris.nane22@ hotmail.com.

Lucinalva Andrade Ataide de Almeida. Doutora em Educação (2008) pela Universidade Federal de Pernambuco (UFPE), tendo também realizado doutorado sanduíche pela Universidade do Porto, é bolsista produtividade em pesquisa 2 e atua como Professora Associada III do Centro Acadêmico do Agreste da Universidade Federal de Pernambuco. Integrante do Grupo de Pesquisa Discursos e Práticas Educacionais.

E-mail: lucinalva.almeida@ufpe.br. 